the liver. There is no great evidence to suggest a genetic linkage to susceptibility for rheumatic diseases such as ankylosing spondylitis or rheumatoid arthritis, but increasing evidence is accumulating that such oxidative systems can be influenced by interleukins, the concentrations of which may certainly fluctuate in chronic inflammatory polyarthritis. ${ }^{20}{ }^{21}$ Whether the rate of drug metabolism is thereby altered with disease activity, whether the magnitude of this effect if present has clinical relevance, and whether this is accentuated or reduced in the elderly are all fundamental questions now requiring resolution.

Set against this extremely complex background, the 11th Harrogate annual day conference in the series 'Growing points in the treatment of rheumatic diseases' was devoted to the theme of 'Antirheumatic drugs in the elderly'. Although it has only proved possible to touch the tip of the iceberg, the ensuing conference report follows.

1 Crooks J. Aging and drug distribution: pharmacodynamics. TChronic Dis 1983; 36: 85-90.

2 Stevenson I H, Salem S A M, Shepherd A M M. Studies on drug absorption and metabolism in the elderly. In: Crooks drug absorption and metabolism in the elderly. In: Crooks J, Stevenson I H, eds. D

3 Tozer T N. Concepts basic to pharmacokinetics. Pharmacol Ther 1981; 12: 109-31.

4 Nation R L, Vine J, Triggs E J, Learoyd B. Plasma levels of chlormethiazole and two metabolites after oral administration to young and aged human beings. Eur $\mathcal{f}$ Clin Pharmacol 1977; 12: 137-46.
5 Vestal R E. Drug use in the elderly: a review of problems and special considerations. Drues 1978; 16: 358-82.

Bender A D. Age and its influence on drug action in adults. Drug Information Bulletin 1969; 3: 153-8.

7 Ewy G A, Kapadia G G, Yao L, Luillin M, Marcus F I Digoxin metabolism in the elderly. Circulation 1969; 39:

8 Macklon A F, Barton M, James O, Rawlins M D. The effect of age on the pharmacokinetics of diazepam. Clin Sci 1980, 59: 479-83.

9 Klotz U, Avant G R, Hoyumpa A, Schenker S, Wilkinson $G R$. The effects of age and liver disease on the disposition and elimination of diazepam in adult man. $\tilde{f}$ Clin Invest 1975; 55: 347-59.

10 Bird H A. The kidney in theumatic diseases. Ann Rheum $D$ is 1989; 48: 1029-30.

11 Prescott L F, Leslie P J, Padfield P. Side effects of benoxaprofen. $\mathrm{Br} \mathrm{Med} \mathcal{F}$ 1982; 284: 1783.

12 Shedden $W$ I H. Side effects of benoxaprofen. $\mathrm{Br} \mathrm{Med} \mathcal{J}$ 1982; 284: 1630 .

13 Taggart H M, Alderdice J M. Fatal cholestatic jaundice in elderly patients taking benoxaprofen. $\operatorname{Br} M e d ~ f 1982 ; 284$ : 1372.

14 Woolf A D, Rogers H J, Bradook I D, Corless D. Pharmacokinetic observations on piroxicam in young adults, middle aged and elderly patients. $\mathrm{Br} f \mathrm{Clin}$ Pharmacol 1983; 16: 433-7.

15 Bollet A J. Piroxicam serum levels in patients treated for rheumatic diseases. Semin Arthritis Rheum 1985; 14 (suppl 1): 25-8.

16 Darrugh A, Gordon A J, Byrne H O, Hobbs D, Casey E. Single-dose and steady-state pharmacokinetics of piroxicam in elderly versus young adults. Eur $\mathcal{F}$ Clin Pharmacol 1985,

17 Richardson C J, Blocka K L N, Ross S G, et al. Effects of age and sex on piroxicam disposition. Clin Pharmacol Ther and sex on piro:

18 Nebert $D$ W. Clinical pharmacology: possible clinical importance of genetic differences in drug metabolism. Br Med 7 tance of genetic differ

19 Sjögvist F, Alvan G. Aging and drug disposition metabolism I Chronic Dis 1983; 36: 31-7.

20 Dinarello $C A$. Interleukin-1 and the pathogenesis of the acute-phase response. $N$ Engl f Med 1984; 311: 1413-8.

21 Dinarello C A. Interleukin-1. Ann NY Acad Sci 1988; 546: 122-32.
The University of Leeds, Royal Bath Hospital, Cormwall Road, Harrognte, Nerth Yortshire HG1 2PS

H A Bird

*The eleventh in a series of annual day conferences devoted to the theme "Growing points in the treatment of rheumatic diseseses' held at the Yorkshire Regional Health Authority, Park Parade, Harrogate, North Yorkshire, on 3 May 1990.

\title{
Antirheumatic drugs in the elderly
}

\author{
H A Bird
}

An audience of 70, drawn from rheumatologists, geriatricians, pharmacists, paramedicals, and industry, discussed a variety of aspects of drug treatment in elderly patients with arthritis during the course of the annual day conference on 'Antirheumatic drugs in the elderly' held at Harrogate on 3 May 1990.

Papers in the morning session, chaired by Dr H A Bird, discussed general aspects of drug treatment in the elderly. Dr E Burns, department of medicine for the elderly, St James's University Hospital, Leeds, reviewed age related changes in drug handling in her keynote address. The number of 'very elderly' (over 85 years) is increasing, and $15 \%$ of the population are now aged over 65 . Thirty per cent of all drugs are prescribed for the elderly and, with concomitant disease, polypharmacy is often necessary with its risk of reduced compliance. The pharmacokinetic changes present in the elderly might be summarised under the headings of absorption, distribution, metabolism, and elimination.
Although the gastric $\mathrm{pH}$ rises and splanchnic blood flow falls with age, changes in absorption are probably not important except for drugs such as sulphasalazine, which undergo activation in the gut. During distribution, changes in serum albumin may affect steady state plasma concentrations of acidic agents, and disease modifying antirheumatic drugs might have greater toxicity. Liver blood flow is reduced, resulting in a decreased ability to metabolise drugs, though interindividual variation in drug metabolism caused by environmental pollutants such as tobacco usually outweighs the effects of aging. At excretion, the elimination of hydrophilic drugs is reduced in predictable fashion as glomerular filtration rate falls steadily with increasing age. The effect of age on hepatic excretion is less easy to predict, but in general there is a reduced clearance of drugs that have a high hepatic extraction ratio. In discussion it was noted that certain subjects seemed to age faster than others physiologically. It behoved 
drug companies to evaluate new compounds in fit and in unfit geriatric groups as well as in those elderly patients receiving other drugs for concomitant disease.

Mr I Buchan, University of Liverpool, described a survey of drugs received by patients attending a regional inpatient rheumatology centre. Fifty five out of 100 patients were at risk of interaction as defined by the appendix of the British National Formulary, but only 11 of these had clinical evidence of interaction. Patients were receiving a mean of 5.4 drugs. The principal consequences of interaction were drowsiness, caused by the simultaneous prescription of two analgesics, and impaired renal function, possibly caused by the coprescription of a non-steroidal anti-inflammatory drug (NSAID) with a diuretic or antihypertensive drug. In discussion the need for better analgesics that lacked a sedative effect in the elderly was emphasised. Negative interactions are also important but tend not to command the attention of those interactions that have clinical consequences.

Drs F Johnston and P McGill, collaborating from the departments of geriatrics and rheumatology at Stobhill General Hospital, Glasgow, surveyed their experience with disease modifying drug treatment in the elderly. Thirty seven elderly patients with rheumatoid arthritis receiving disease modifying drugs were assessed to determine if benefits outweighed risks. A surprisingly large number of patients received steroids with benefit. Gold had proved easy to use in view of the injection formulation and, provided that adequate precautions were taken, was safe. Azathioprine had been used for its steroid reducing properties, and patients receiving NSAIDs had developed a variety of side effects as a result of them. It was argued that disease modifying drugs, allowing the reduced use of NSAIDs in rheumatoid arthritis, were preferred in the elderly. The risk of oncogenesis was low in this group and the only major problem, perhaps peculiar to Glasgow, had been the reactivation of tuberculosis following the introduction of steroids.

Dr A Taggart, Musgrave Park Hospital, Belfast, presented a pharmacokinetic study on the handling of benorylate in patients with arthritis. The median half life of free salicylic acid was greater in patients with osteoarthritis (10.6 hours) than in those with rheumatoid arthritis ( $7 \cdot 7$ hours). Large differences in the steady state concentration of free and total salicylic acid were found between controls and patients. The average steady state concentration of paracetamol was greater $(p=0.04)$ in arthritic patients than in controls. The pharmacokinetics suggested that the increased toxicity associated with full benorylate dosage in elderly arthritic patients is due partly to reduced clearance but mainly to lower body weight. This study further illustrated the need for the adequate evaluation of new drugs in the elderly, the age group for which they were most commonly prescribed, before introduction.

The last keynote talk of the morning was given by $\mathrm{Dr}$ Ingvar Bjarnason of Northwick Park Hospital, who described the changes in small intestinal permeability that can be caused by NSAIDs and the propensity of these drugs to cause stricture formation ('diaphragm disease'). Much of his work has been done on a group of patients aged between 55 and 80 years and, in discussion, the possibility that this might be an effect related to age was raised as members of the audience had found it less commonly in younger patients. The phenomenon seemed to be related to prostaglandin and might be alleviated by the co-administration of protective prostaglandins or the use of pro-NSAIDs.

The afternoon session, chaired by Professor V Wright, dealt in greater depth with renal aspects and compliance. Dr J Eccles, St James's University Hospital, Leeds, reviewed the changes that occur as the kidney ages. Glomerular filtration rate falls, leading to a fall in tubular excretion. There is a reduction in the number of glomeruli, some of which are even lost as early as the seventh month of intrauterine life. Nonsteroidal anti-inflammatory drugs were able to interact with the kidney at a variety of sites, and the standard advice to reduce the dose prescribed in the elderly remained valid.

Dr L Simon, Harvard Medical School, Boston, Massachusetts, reinforced these principles with his pharmacokinetic study of naproxen in elderly patients with mild to moderate renal impairment. After three days washout without NSAIDs, naproxen $375 \mathrm{mg}$ twice daily was given for 14 days. Changes in creatinine clearance, serum creatinine, and diastolic blood pressure were correlated with changes in serum thromboxane and urinary prostaglandins. Serum thromboxane $B_{2}$ fell and urinary prostaglandin $E_{2}$ was reduced during treatment. Nevertheless, diastolic blood pressure remained unaltered and there was no significant impairment in creatinine clearance or serum creatinine. All patients had a baseline creatinine clearance of $<70 \mathrm{ml} / \mathrm{min}$ or a serum creatinine of $>115 \mu \mathrm{mol} / \mathrm{l}$, and it was concluded that naproxen in this dose could be safely prescribed for patients with impaired renal function. In discussion the geriatricians drew attention to the relative normality of these patients and the additional problems encountered when the elderly experienced simultaneous fluid depletion in an acute illness.

Mr Buchan, Liverpool, then presented his survey of serum creatinine in a group of arthritic patients with a variety of diagnoses taking either NSAIDs, analgesics, or both. Although creatinine deteriorated with age, there was no significant difference between serum creatinine in patients receiving or not receiving NSAIDs or in male or female patients matched for age. This provided further support for the relative safety of NSAIDs, used in modest dosage, provided that there was no simultaneous acute illness.

The section on compliance began with a review by Dr T Pullar, General Infirmary at Leeds. Methods available for assessing compliance included return tablet count, patient interview, pharmacological methods, and electronic monitoring. Return tablet count and interview were subject to certain criticisms, and pharmacological methods (such as the incorporation of a small marker molecule, perhaps a 
subclinical dose of phenobarbitone, in tablets of active drug) were preferred. They were also less expensive than electronic monitoring, which only indicated opening of the bottle and did not confirm that the tablet had then been taken. An overview of all such studies suggested that full compliance (95-100\% of the dose reliably taken) was achieved in 5-20\% of patients and sloppy compliance $(50-90 \%$ of each dose taken) was achieved in $40-70 \%$ of patients. The number of patients showing either low or non-compliance was usually less than $10 \%$. Interestingly, older patients displayed better compliance with warfarin than younger patients. Whether compliance correlated with intelligence in the elderly, or whether compliance was better with drugs that made you feel better rather than those that made you feel worse, had not been adequately studied.

Dr Burns (Leeds) had studied cognitive function and patients' knowledge about drug treatment in 207 geriatric outpatients. Patient/ doctor agreement on the number of drugs taken fell with increasing age, independently of change in cognitive function, though the patients ability to recall information about drugs was related to cognitive function. Many patients said their knowledge of drugs was inadequate and would have liked more information. Although the audience was in broad agreement with the findings, there was less agreement on the best way to improve the provision of information, cases being made for its delivery either by the doctor, the pharmacist, or even by a lay assistant.

Mrs R Hopkins, General Infirmary at Leeds, had also studied awareness of prescribed drugs in 317 patients. Under the age of 65 more patients knew details of their drugs and over the age of 75 only one third of patients studied were able to name the tablets they were taking. Seventy five per cent of the over 75 s attending rheumatology clinic had been receiving an NSAID. The most elderly were particularly likely to be taking diuretic or hypnotic drugs.

Mrs J Hill, Royal Bath Hospital, Harrogate, described the use of a questionnaire to determine what patients knew about the disease and its treatment. Eighteen elderly patients with rheumatoid arthritis knew less than a group of younger patients with the same disease, assessed by the same questionnaire. The elderly found it particularly hard to distinguish between NSAIDs and disease modifying drugs and often did not known which disease the drugs were for. The need to back up patient information forms provided with tuition was emphasised. In discussion some had found self medication improved patient knowledge, but only a small proportion of rheumatic patients enter hospital to participate in this. Information sheets in general needed to be simple, though a proportion of patients, perhaps greater than normally expected, benefited from a more detailed information sheet.

The conference ended with two brief papers by Dr J Young, St Luke's Hospital, Bradford, on more clinical aspects. He first reviewed nonarthritic hip pain in the elderly. In this group a differential diagnosis of metastasis, Paget's disease, and fractured neck of femur, even if not apparent by radiography, all needed to be considered as mimics of osteoarthritis at the hip joint. Geriatricians were familiar with the 'new braces' sign, indicating recent rapid weight loss, and the 'new walking stick' sign, indicating an acute onset of recent hip pain even if the history was a little confusing. The second paper on the aging spine reviewed the economic impact of back pain found in the elderly who were employed compared with the apparent amelioration of back pain as the patient got older and left work. Reasons discussed for this included retirement, modified pain perception in the elderly, and, possibly, stabilisation of the lumbar spine as degenerative joint disease intervened, though it was accepted that this also caused back pain in its own right. 